\title{
Compressed $\mathrm{CO}_{2}$ technologies for the recovery of carotenoid-enriched
}

\section{extracts from Dunaliella salina with potential neuroprotective activity}

Mónica Bueno ${ }^{1}$, Clementina Vitali ${ }^{1,2}$, José David Sánchez-Martínez ${ }^{1}$, José Antonio Mendiola $^{1}$, Alejandro Cifuentes ${ }^{1}$, Elena Ibáñez $^{1}$, Miguel Herrero $^{1 *}$

${ }^{1}$ Laboratory of Foodomics, Institute of Food Science Research, CIAL, CSIC, Nicolás Cabrera 9, 28049 Madrid, Spain.

${ }^{2}$ Unit of Food Science and Nutrition, Faculty of Medicine - Campus Bio-Medico University of Rome, via Álvaro del Portillo 21, 00128 Rome, Italy

*Corresponding author:

Dr. Miguel Herrero, Laboratory of Foodomics, Institute of Food Science Research,

CIAL (CSIC), Nicolás Cabrera 9, 28049 Madrid, Spain,

e-mail:m.herrero@csic.es

Tel.: +34 910017946; fax: +34 910017905.

ORCID IDs:

M. Herrero: 0000-0002-7214-6653

E. Ibáñez: 0000-0003-2127-8303

J. A. Mendiola: 0000-0001-6709-349X

A. Cifuentes: 0000-0002-7464-0217

M. Bueno: 0000-0002-5904-8506

J. D. Sánchez-Martínez: 0000-0003-3134-5960 


\section{ABSTRACT}

2 Natural carotenoids from microalgae have raised a huge interest for their potential health

3 benefits. Among microalgae species with high carotenoid content, Dunaliella salina has

4 been highlighted since it is able to accumulate relatively high amounts of $\beta$-carotene and

5 other carotenoids of industrial interest when grown under specific conditions. In the

6 present contribution, extractions based on carbon dioxide under sub- and supercritical

7 conditions have been optimized to improve the recovery of carotenoids and extracts purity

8 from $D$. salina. An experimental design was employed to investigate the effect of pressure

9 and temperature variations ranging from 250 to 400 bar and from 15 to $45{ }^{\circ} \mathrm{C}$,

10 respectively. The chemical characterization of the carotenoids extracts was carried out by

11 HPLC-DAD. Moreover, inhibition of the acetylcholinesterase activity of all the extracts

12 was measured by using a recently developed in-vitro fluorescence methodology. High

13 carotenoid yield and purity were obtained at $302-313$ bar and $45{ }^{\circ} \mathrm{C}$. Nine carotenoids

14 were identified and three other compounds were recognized as carotenoids and

15 quantified. Acetylcholinesterase activity inhibition could be satisfactorily explained by a

16 partial least-square model (63\% explained variance in cross-validation) built considering

17 the chemical composition of the different extracts. The model indicates a positive effect

18 of lutein, 15 -cis- $\beta$-carotene and the negative effect of zeaxanthin, cryptoxanthin and the

19 ratio 9 -cis- $\beta$-carotene/all-trans- $\beta$-carotene and 9 -cis- $\beta$-carotene/total carotenoids in the

20 inhibition of acetylcholinesterase enzyme.

\section{KEYWORDS:}

$23 \quad \beta$-carotene; carotenoids; compressed $\mathrm{CO}_{2}$ extractions; Dunaliella salina; in-vitro 24 fluorescence AChE methodology. 
27 At present, there is an increasing demand for natural bioactive compounds able to provide health benefits. In this regard, microalgae are promising microorganisms that can play a key role in the bio-based economy, since they may serve as a continuous and reliable source of safe bioactive natural products. Dunaliella salina is a green microalga able to accumulate relatively high amounts of $\beta$-carotene when grown under specific conditions. $\beta$-carotene in $D$. salina can constitute over $80 \%$ of the total carotenoid content ${ }^{1}$; in most microalgae, there is not a major component representing more than $70 \%$ of total carotenoids $^{2}$. Although this compound is the main terpenoid in this microalga species, other carotenoids related to its biosynthetic pathway could also be of industrial interest. Carotenoids have health-promoting properties such as anti-cancer, antioxidant, or antidiabetic activities ${ }^{3}$. Furthermore, when compressed fluids technologies using green solvents are used for their extraction, these compounds are compliant with processes and regulations implemented in food, cosmetic, and pharmaceutical sectors ${ }^{4}$.

As every aspect related to sustainability increases their importance and relevance nowadays, the development of new green extraction protocols to obtain bioactives from natural sources is a must. Compressed fluids can provide interesting advantages in the search for processes adapted to the recovery of valuable natural compounds ${ }^{4}$. The use of greener solvents in combination with greener techniques has several benefits involving less time, a reduction in the employed energy and produced wastes ${ }^{5}$. Among them, supercritical fluid extraction (SFE) and pressurized liquid extraction (PLE) are the most popular and widely used ${ }^{4}$. Although the use of compressed fluids has previously been 48 described for the extraction of carotenoids from $D$. salina $a^{6-9}$, the particular extraction conditions have to be tuned according to the existing biomass and its specific carotenoid composition. Previously published works dealing with the use of SFE have focused on 
51 the antioxidant and/or antimicrobial effect of the extracts ${ }^{10,11}$. However, up to know, the

52 potential of $D$. salina extracts rich in carotenoids to inhibit acetylcholinesterase (AChE)

53 activity has not been explored so far.

54 Alzheimer's disease is one of the main neurodegenerative disorders causing dementia.

55 This disease has a multifactorial origin and, despite its importance, there is no effective

56 clinical treatment for this chronic issue. Current treatments are just focused on the

57 alleviation of symptoms. For this reason, the prevention of the development of this disease

58 is of utmost importance. In this regard, dietary components have been highlighted as

59 potential effective agents towards the prevention of Alzheimer's disease, among other

60 neurodegenerative diseases ${ }^{12}$. In particular, terpenoids with a wide array of different

61 chemical structures, including carotenoids, have been demonstrated to retain a good

62 preventive potential against neurodegeneration ${ }^{13,14}$, although their molecular mechanisms

63 of action have not comprehensively been described so far. One of the possible targets

64 through which the bioactivity of these components may be exerted is the inhibition of

65 acetylcholinesterase (AChE) activity, as a significant reduction of acetylcholine levels in

66 the hippocampus and cortex of the brain of Alzheimer's disease patients has been

67 confirmed $^{15}$. As a result, AChE inhibitors may not only produce an increase in

68 acetylcholine levels in the brain but also reduce and prevent the formation of $\beta$-amyloid

69 plaques, protecting neurons from neurodegeneration ${ }^{16}$. For this reason, the study of the

70 potential of $D$. salina carotenoids to inhibit the activity of this enzyme is interesting.

71 However, up to now, this activity has not been thoroughly studied.

72 One of the possible reasons for this lack of studies is the fact that there was not an effective methodology for determining this activity in colored extracts, such as those containing carotenoids. The new in-vitro AChE fluorescent methodology developed by SánchezMartínez et al. ${ }^{17}$ overcomes this problem. In this new methodology, 5,5'-dithio-bis (2- 
76 nitrobenzoic acid) (DNTB) reagent is replaced by 4-(amino-sulfonyl)-7-fluoro-2,1,3-

77 benzoxadiazole (ABD-F). The thiols originated in the hydrolysis reaction between AChE and their acetylthiocholine iodide (ATCI) substrate react with ABD-F producing a fluorescent complex ${ }^{18}$. Furthermore, the presence of carotenoids has been described in

80 the human brain ${ }^{19}$, which means that they could cross the blood-brain barrier (BBB), and

81 therefore they could be active against neurodegenerative diseases.

82 The aim of the present work was to evaluate the effect of a wide range of sub- and supercritical conditions on the extraction of carotenoids from $D$. salina and their effect in the inhibition of AChE activity, looking more specifically for differences in carotenoids bioactivity due to variations on their chemical structure. For this purpose, the extracts were chemically characterized and a mathematical model was built to predict their AChE inhibition activity.

\section{MATERIALS AND METHODS}

\section{Sample and reagents}

91 D. salina freeze-dried microalgae biomass was supplied by A4F (Lisbon, Portugal) and

92 were stored in the dark at a temperature of $-18^{\circ} \mathrm{C}$ packed in the absence of oxygen until 93 utilization. For the sub- and supercritical fluid extraction, premier quality $\mathrm{CO}_{2}$ was provided by Carburos Metálicos (Madrid, Spain) and sea sand by Panreac Quimica (Barcelona, Spain). HPLC-grade ethanol was purchased from LabScan (Gliwice, Poland), methyl tert-butyl ether (MTBE; 100.0\%), and LC-MS grade methanol were from (VWR,

97 Barcelona, Spain). Washed glass wool, HPLC-grade acetone ( $\geq 99,9 \%)$, HPLC-grade tetrahydrofuran, butylated hydroxytoluene (BHT), acetylcholinesterase (AChE) Type VI-

99 S from Electrophorus electricus, acetylthiocholine iodide (ATCI), Trizma hydrochloride 100 (Tris- $\mathrm{HCl})$, all-trans- $\beta$-carotene $(\geq$ of $97 \%)$, lutein $(\geq 96 \%)$ and zeaxanthin $(\geq 95 \%)$ 
101 standards were obtained from Sigma-Aldrich (Madrid, Spain). 4-(Aminosulfonyl)-7-

102 fluoro-2,1,3-benzoxadiazole (ABD-F) and galantamine hydrobromide were purchased

103 from TCI Chemicals (Tokyo, Japan). Water was purified using a Milli-Q system

104 (Millipore Corp., Billerica, MA, USA).

105

106 Experimental design and statistical analysis

107 Experimental design and its statistical assessment were carried out using Statgraphics

108 Centurion XVI software (StatPoint Technologies, Inc., Warrenton, VA, USA). The

109 influence of extraction temperature and pressure on D. salina extracts was studied using

110 a three-level factorial experimental design. A total of 12 extractions ( 9 points of the

111 factorial design and 3 center points to consider the experimental error) were run in

112 randomized order. By using this design, two factors were tested at three different levels:

113 pressure at 250,325 , and 400 bar and temperature at 15,30 , and $45^{\circ} \mathrm{C}$. The selected

114 response variables were extraction yield (expressed as the percentage of extract weight

115 per initial algae weight), carotenoid yield or extraction efficiency (expressed as mg of

116 carotenoids extracted per g of algae), and the purity of the extract (or total carotenoids

117 content) (expressed as $\mathrm{mg}$ of carotenoids per $100 \mathrm{mg}$ of extract).

118 The obtained data were optimized applying response surface methodology (RSM). The

119 quadratic model proposed for each response variable $\left(\mathrm{Y}_{\mathrm{i}}\right)$ follows equation 1:

$$
\mathrm{Y}_{\mathrm{i}}=\beta_{0}+\beta_{1} \mathrm{P}+\beta_{2} \mathrm{~T}+\beta_{1,1} \mathrm{P}^{2}+\beta_{2,2} \mathrm{~T}^{2}+\beta_{1,2} \mathrm{PT}+\text { error }
$$

122 where $\mathrm{P}$ stands for pressure (bar) and $\mathrm{T}$ for temperature $\left({ }^{\circ} \mathrm{C}\right)$, the independent variables, while $\beta_{0}$ is the intercept, $\beta_{1}$ and $\beta_{2}$ are the linear coefficients, $\beta_{1,1}$ and $\beta_{2,2}$ are the quadratic coefficients, $\beta_{1,2}$ is the interaction coefficient, and error is the error variable. Those parameters were estimated by multiple linear regression (MLR) and their effect on the 
126 model and statistical significance, for each response variable, were illustrated in a Pareto

127 chart. The goodness of fit of the model was evaluated by the coefficient of determination

$128\left(\mathrm{R}^{2}\right)$ and the residual standard deviation (RSD) from the ANOVA table. The model also

129 provided the optimum extraction conditions which maximized each response variable and

130 results were graphically represented in a surface plot.

131

132 Compressed carbon dioxide extractions

133 Extractions were performed in a homemade compressed fluids extraction system (Figure

$134 \mathrm{~S} 1$, Supporting information). The $\mathrm{CO}_{2}$ from a cylinder was cooled and then compressed 135 by a $\mathrm{CO}_{2}$ pump from Jasco (Tokyo, Japan). Afterward, the liquid $\mathrm{CO}_{2}$ is preheated and 136 pushed towards the oven, where the extraction cell containing the algae material is placed.

137 The flow rate was set at $4.5 \mathrm{~mL} / \mathrm{min}$. The pressure was controlled adjusting the opening 138 of two needle valves. The extraction cell was filled with a mixture of $100 \mathrm{mg}$ of sample 139 and $2 \mathrm{~g}$ of sand placed between two layers of glass wool. Subsequently, the extracts were 140 collected in a liquid ethanol trap. The extract recovering system was cooled by the $\mathrm{CO}_{2}$ 141 expansion and protected from light by aluminum foil. The extraction time was fixed at 90 $142 \min$. The extractions were carried out following a randomized run order. Each extract was 143 transferred to a previously weighted glass vial and evaporated by a gentle nitrogen stream.

144 Extracts containing $0.05 \%(\mathrm{w} / \mathrm{w})$ BHT were stored in the dark at $-20{ }^{\circ} \mathrm{C}$.

\section{Conventional extraction}

147 For the conventional solid-liquid extraction (SLE) protocol used as a benchmark method, $148200 \mathrm{mg}$ of microalgae were mixed with $20 \mathrm{~mL}$ of HPLC-grade acetone containing $0.1 \%$ $149(\mathrm{w} / \mathrm{v})$ BHT, as described elsewhere ${ }^{20}$. The extraction was performed in a stirred 150 thermostatic bath (Selecta, Barcelona, Spain) operating at $500 \mathrm{rpm}$ and $20{ }^{\circ} \mathrm{C}$ in the dark 
151 for $24 \mathrm{~h}$. After refrigerated centrifugation (5804 R Eppendorf, Hamburg, Germany) at

$15210,000 \mathrm{rpm}$ and $4{ }^{\circ} \mathrm{C}$ for $10 \mathrm{~min}$, the supernatant was collected, poured in a previously 153 weighted glass vial and evaporated by using a gentle nitrogen stream. Extracts were stored 154 in the dark at $-20^{\circ} \mathrm{C}$.

155

156 Characterization of carotenoids by liquid chromatography coupled to diode array 157 detection

158 Qualitative and quantitative analyses of carotenoids were performed using an Agilent 1591100 series liquid chromatograph (Santa Clara, CA, USA) equipped with a diode-array 160 detector (DAD) and using a YMC-C30 reversed-phase column $(250 \mathrm{~mm} \times 4.6 \mathrm{~mm}$ i.d., 5

$161 \mu \mathrm{m}$ particle size; YMC Europe, Schermbeck, Germany) and a pre-column YMC-C30 (10 $162 \mathrm{~mm} \times 4 \mathrm{~mm}$ i.d., $5 \mu \mathrm{m}$ particle size). A solution of methanol/MTBE/water $(90: 7: 3 \mathrm{v} / \mathrm{v} / \mathrm{v})$

163 was used as mobile phase A, while methanol/MTBE (10:90 v/v) was employed as mobile 164 phase $\mathrm{B}$. The flow rate was $0.8 \mathrm{~mL} / \mathrm{min}$ and the injection volume was $10 \mu \mathrm{L}$. The 165 chromatographic separation was run according to the following gradient: $0 \mathrm{~min}, 30 \% \mathrm{~B}$;

$16615 \min , 40 \% \mathrm{~B} ; 18 \min , 80 \% \mathrm{~B} ; 23 \mathrm{~min}, 100 \% \mathrm{~B} ; 25 \min , 0 \% \mathrm{~B} ; 28 \mathrm{~min}, 30 \% \mathrm{~B} ; 30$

$167 \mathrm{~min}, 30 \% \mathrm{~B}$. The samples were dissolved in HPLC-grade ethanol at an appropriate 168 concentration $(0.1-1.0 \mathrm{mg} / \mathrm{mL})$ and filtered through $0.45 \mu \mathrm{m}$ nylon filters. Absorption 169 spectra were recorded from 240 to $770 \mathrm{~nm}$ using the DAD whereas the quantification of 170 carotenoids was carried out at $450 \mathrm{~nm}$. The instrument was controlled by LC ChemStation 171 3D Software Rev. B04.03 (Agilent Technologies, Santa Clara, CA, USA).

172 The identification of carotenoids was performed by comparison with available 173 commercial standards, known absorption spectra, retention times, and elution orders 174 reported in the literature. 
175 For the calibration curves, stock solutions of zeaxanthin and lutein were prepared in

176 ethanol at a concentration of $2 \mathrm{mg} / \mathrm{mL}$. Then six serial dilutions were performed and

177 injected in triplicate. For $\beta$-carotene calibration curve, the stock solution was dissolved in

178 THF (1.5 mg/mL), and eight aliquots at different concentrations were prepared in ethanol

179 and injected in triplicate. Since no standards of $\beta$-carotene isomers were available, the

180 quantification of the different isomers was performed using the pure all-trans- $\beta$-carotene

181 standard, assuming the response factor would be the same. Amounts of compounds

182 assigned as carotenoids that could not be unequivocally identified were also estimated

183 using the aforementioned calibration curves.

184

185 Acetylcholinesterase inhibitory capacity

186 The acetylcholinesterase (AChE) inhibitory capacity of the extracts was determined by

187 fluorescent enzyme kinetics as developed by Sánchez-Martínez et al. ${ }^{17}$. Briefly, a mixture

188 of $100 \mu \mathrm{L}$ extract sample diluted in water-ethanol (50:50, v/v), $100 \mu \mathrm{L}$ Tris-HCl buffer at

$189 \mathrm{pH} 8$ and $25 \mu \mathrm{L}$ of AChE diluted in buffer $(0.8 \mathrm{U} / \mathrm{mL})$ was incubated for 10 minutes. In

190 the reference enzymatic activity assay, $100 \mu \mathrm{L}$ of water-ethanol (50:50, v/v) containing

191 the same amount of BHT than samples were added in the solution assay, to take into

192 account the possible effect of BHT in the enzymatic activity. Then, $25 \mu \mathrm{L}$ of $125 \mu \mathrm{M}$

193 ABD-F in the buffer and $50 \mu \mathrm{L}$ of $1.4 \mathrm{mM}$ ATCI in water were added to each well.

194 Excitation and emission wavelengths (389 $\mathrm{nm}$ and $513 \mathrm{~nm}$, respectively) were recorded

195 in a fluorescence reader (Synergy HT, BioTek Instruments, Winooski, VT, USA) every

196 minute for 10 minutes at $37^{\circ} \mathrm{C}$.

197 This kinetic measurement is needed to obtain $V_{\text {mean }}$ value. $V_{\text {mean }}$ corresponds to enzymatic

198 mean velocity achieved during kinetic measurement. Percentage of inhibition degree

199 (ID\%) was calculated through equation 2: 
$200 \quad I D \%=\frac{V_{O}-V_{1}}{V_{0}} \times 100$

202 where $V_{0}$ and $V_{1}$ are the $V_{\text {mean }}$ of enzyme kinetic without and with extract sample,

203 respectively. Galantamine hydrobromide diluted in water-ethanol (50:50, v/v) was used

204 as inhibitor control.

205 Three independent assays of each extraction were carried out for AChE assay. Results

206 were expressed as the concentration of extract that causes $50 \%$ inhibition $\left(\mathrm{IC}_{50}\right.$ value), for

207 which different measurements of ID\% at seven concentrations were needed.

209 Life Cycle Assessment (LCA)

210 The two extraction processes were evaluated in terms of environmental performance

211 according to LCA procedure using the software SimaPro 8 (Pré Consultants B.V,

212 Amersfoort, The Netherlands) using the calculation method ILCD (International

213 reference Life Cycle Data system) ${ }^{21}$, using the SimaPro option "ILCD 2011 Midpoint+

214 V1.08 / EU27 2010, equal weighting”. To be able to do this comparison between SFE

215 using $\mathrm{CO}_{2}$ and SLE using acetone, the best carotenoid yield obtained in both cases was

216 used. The functional unit (FU) to which the environmental impact categories were

217 normalized is here defined as $1 \mathrm{~g}$ of carotenoids. Besides, Figure 1 represents the flowchart

218 of the steps followed to obtain $D$. salina extract by both processes, the technical system

219 boundaries considered in the LCA analysis are inside the dotted box. A gate-to-gate

220 approach was considered, where the upstream and downstream steps linked to the

221 extraction period were not included. The differences in the quantity of raw material

222 employed were estimated to have a minor impact on the overall environmental

223 performance. 


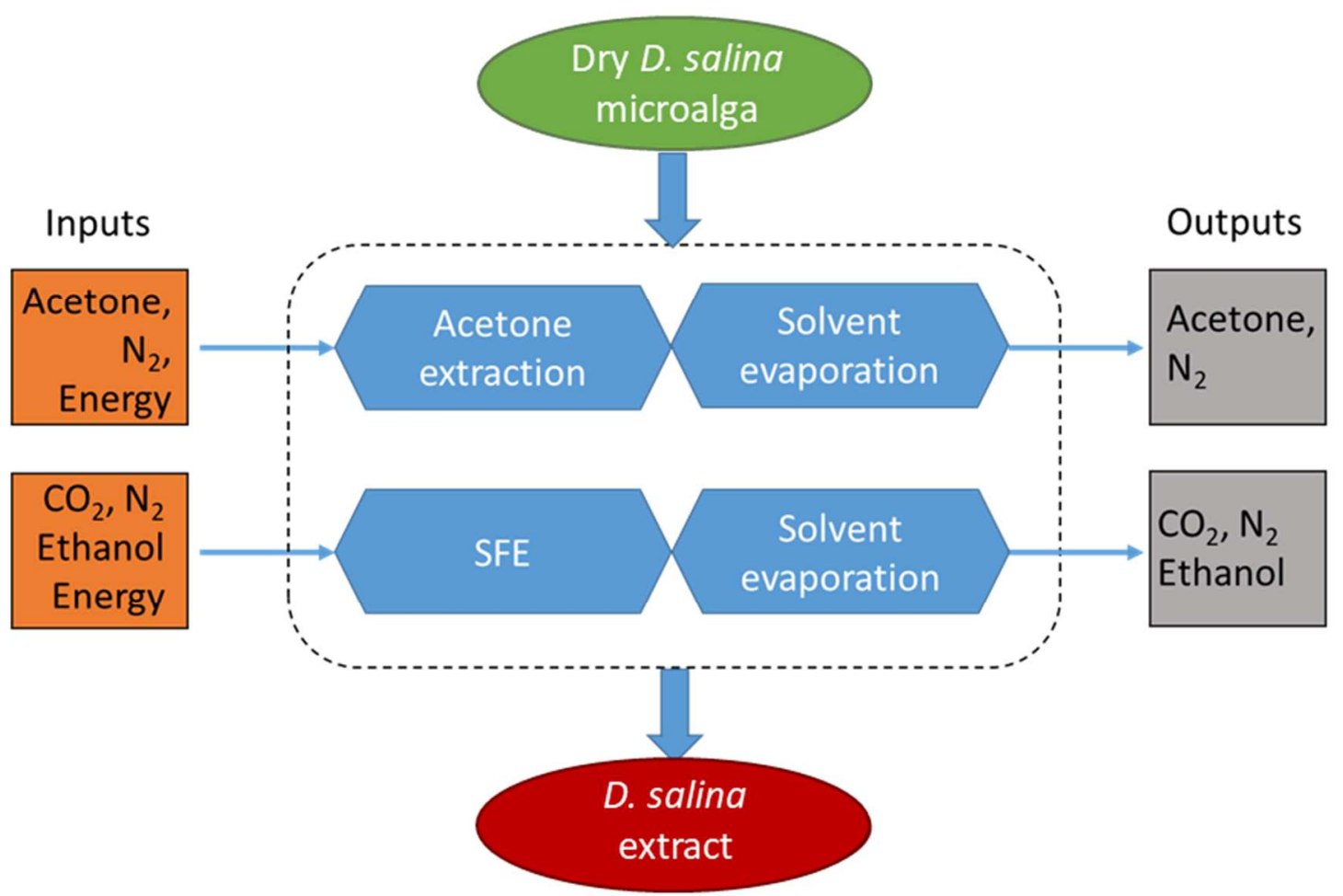

225 Figure 1. System boundaries considered for the LCA calculation to compare SLE and 226 SFE to obtain $D$. salina carotenoids.

\section{Statistical Analysis}

229 Principal Component Analysis (PCA) of the chemical composition of the extracts was 230 performed using XLSTAT (Addinsoft, version 2015). Partial least square regression 231 (PLSR) model was developed using the statistical software The Unscrambler 9.7

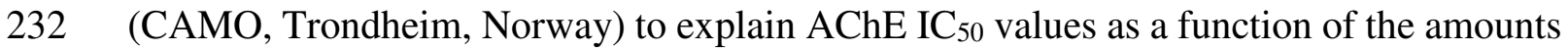
233 of carotenoids present in the extracts. PLS model was obtained taking into account cross234 validation criteria. In this sense, the model was built in iterations leaving out one extract sample in each iteration. The predicted result for the extract that was left out, was used to

236 calculate the model error. A reiterative process was carried out until every extract sample 237 has been excluded once; then all the prediction residuals are used to calculate the 238 validation residual variance and the root mean square error (RMSE) of the prediction. 
239 The slope of the regression curve between real and predicted Y variables $(\mathrm{m})$ we also

240 used to evaluate the predictive ability of the model.

\section{RESULTS AND DISCUSSION}

\section{Extraction of carotenoids from Dunaliella salina microalgae}

244 The optimization of compressed $\mathrm{CO}_{2}$ extraction conditions was performed using an 245 experimental design. Sub- and supercritical $\mathrm{CO}_{2}$ extractions have already been 246 successfully applied by several authors to extract carotenoids from $D$. salina $a^{6-9,11}$. It

247 makes sense that most authors choose $\mathrm{CO}_{2}$ as extraction solvent since it is inert, non248 toxic, has a low cost, is abundant and easy to recover and, furthermore, products 249 containing extracts obtained with food grade $\mathrm{CO}_{2}$ are safe in terms of human health ${ }^{22}$.

250 That is why $\mathrm{CO}_{2}$ is considered a GRAS (generally recognized as a safe) solvent. Different pressure $\left(100-500\right.$ bar) and temperature $\left(40-60{ }^{\circ} \mathrm{C}\right)$ conditions above the $\mathrm{CO}_{2}$ supercritical point have previously been studied to optimize the extraction process and to suggest predictive models explaining the attainable yield of carotenoids as a function of these two variables $^{6,8}$. Besides, in an early study developed in our laboratory ${ }^{11}$, the effect of pressure and temperature on the antioxidant activity of the extracts was evaluated.

However, to cover a wider range of conditions (and thus, a wide range of carbon dioxide physico-chemical properties), in the present contribution sub- and supercritical $\mathrm{CO}_{2}$ process conditions were tested and optimized to improve the extraction yield, the extraction efficiency (carotenoids yield) and purity (total amount of carotenoids).

260 Moreover, it has to be considered that the specific strain and growing conditions used will significantly influence both the carotenoid content inside the cells as well as the extraction process. Therefore, ad-hoc optimization processes are highly desired to obtain optimum results. To do that, pressures between 250 and 400 bar, and temperatures ranging from 15 
264 to $45{ }^{\circ} \mathrm{C}$ have been investigated. All the response variables studied including the $\mathrm{AChE}$

265 inhibitory activity measured for all the obtained extracts are summarized in Table 1.

266

267 Table 1. Factor levels of the experimental design and results obtained for yield,

268 efficiency, purity, and AChE inhibition depending on extraction pressure and temperature

269 employed.

$\begin{array}{ccccccc}\text { Exp. } & \begin{array}{c}\text { Pressure } \\ (\text { bar })\end{array} & \begin{array}{c}\text { Temperature } \\ \left({ }^{\circ} \mathrm{C}\right)\end{array} & \begin{array}{c}\text { Extraction } \\ \text { yield }(\%)\end{array} & \begin{array}{c}\text { Efficiency } \\ \text { Carotenoid yield } \\ (\mathrm{mg} / \mathrm{g} \text { of alga })\end{array} & \begin{array}{c}\text { Purity } \\ \text { Total carotenoids } \\ (\mathrm{mg} / 100 \text { mg of extract })\end{array} & \begin{array}{c}\text { AChE } \\ (\mu \mathrm{g} / \mathrm{mL})\end{array} \\ 1 & 325 & 30 & 11.96 & 56.04 & 46.86 & 74.07 \\ 2 & 325 & 15 & 7.34 & 26.77 & 36.47 & 48.31 \\ 3 & 325 & 30 & 10.22 & 52.40 & 51.27 & 62.54 \\ 4 & 400 & 15 & 7.80 & 18.15 & 23.27 & 74.21 \\ 5 & 325 & 30 & 11.43 & 51.69 & 45.22 & 50.12 \\ 6 & 400 & 30 & 12.11 & 28.23 & 23.31 & 48.31 \\ 7 & 250 & 45 & 12.70 & 57.82 & 45.53 & 37.84 \\ 8 & 250 & 30 & 9.18 & 35.46 & 38.63 & 41.85 \\ 9 & 400 & 45 & 12.99 & 51.91 & 39.96 & 47.49 \\ 10 & 325 & 45 & 10.54 & 41.89 & 39.74 & 18.85 \\ 11 & 250 & 15 & 7.41 & 26.52 & 35.79 & 56.20 \\ 12 & 325 & 30 & 12.75 & 54.24 & 42.54 & 45.88 \\ \text { SLE } & 1 & 20 & 24.52 & 45.04 & 18.37 & 99.39\end{array}$

270 SLE: solid-liquid extraction

271

272 As can be seen, extraction yields ranged from 7.34 to $12.99 \%$, which can be considered

273 quite high compared to a maximum of $6.60 \%$ reported in previous studies ${ }^{9,11}$ were

274 obtained. A model equation that explains $79.5 \%$ of the variation of extraction yield

275 (Equation 3), indicates that the linear effect of temperature is the most important term in

276 the model, with a positive significant correlation (Figure S2, Supporting information).

$278 \quad \mathrm{Y}_{\mathrm{y}}=0.88667-0.01096 \mathrm{P}+0.56856 \mathrm{~T}+0.00003 \mathrm{P}^{2}-0.00002 \mathrm{PT}-0.00682 \mathrm{~T}^{2}$ 
where, $\mathrm{Y}_{\mathrm{y}}$ stands for extraction yield, $\mathrm{P}$ for pressure (in bar), and $\mathrm{T}$ for temperature (in $\left.{ }^{\circ} \mathrm{C}\right)$.

282 The non-significant terms from the model were excluded and the mathematical model was refitted giving a new equation (Equation 4$)$ with higher deviation $\left(\mathrm{R}^{2}=62.0 \%\right)$ but

284 with more physical credibility of the results.

$285 \quad Y_{y}=5.976+0.152 T$

287 Other previously studied models ${ }^{11}$, instead, reported that pressure was the most relevant parameter and stated that the extract yield positively correlated with pressure and negatively with temperature. A higher $\mathrm{CO}_{2}$ density is, in fact, responsible for an improved solvation power towards carotenoids and other lipids, which are supposed to be the main constituents of the extracted material from D. salina. As shown in Table 1, in the present work, extractions carried out using liquid $\mathrm{CO}_{2}$ (those at $15^{\circ} \mathrm{C}$ ) did not show a remarkably high yield $(<8 \%)$ which is probably related with differences in the initial biomass compared to other published reports. As significant differences in chemical composition and even cell morphology could be due to the specific growing conditions and the particular strain grown ${ }^{23-25}$, it is necessary to carefully optimize the extraction conditions in each case to maximize the recovery of carotenoids. Furthermore, it has been reported that at constant pressure the solubility of $\beta$-carotene decreases with increasing density in the supercritical region ${ }^{26,27}$; this fact is confirmed in the present work, as can be observed comparing experiments 4, 6 and 9 in terms of total carotenoids. Indeed, density, despite enhancing the solvation power of $\mathrm{CO}_{2}$, correlates negatively with its diffusivity. 
305 A model was computed on the basis of the carotenoid yields (Table 1), expressed as mg

306 of carotenoids per g of extracted alga. The non-significant terms of the initial model

307 (quadratic temperature and the interaction between temperature and pressure) were

308 excluded and the following equation was found (Equation 5):

309

$310 \quad Y_{E}=-167.258+1.203 P+0.891 T-0.002 P^{2}$

311

312 where, $\mathrm{Y}_{\mathrm{E}}$ stands for carotenoid extraction efficiency, $\mathrm{P}$ for pressure (bar), and $\mathrm{T}$ for

313 temperature $\left({ }^{\circ} \mathrm{C}\right)$. The model presents an $\mathrm{R}^{2}$ of $69.1 \%$ and predicts the optimum extraction

314 conditions as 312.6 bar and $45.0^{\circ} \mathrm{C}$, with a predicted value of $60.8 \mathrm{mg}$ of carotenoids/g

315 alga. RSD\% calculated was $9.1 \%$. The corresponding estimated response surface is

316 shown in Figure 2A. As for the total extraction yield, linear temperature correlated

317 positively and represents the only significant term $(p<0.01)$, however the quadratic

318 pressure term seems to have a negative trend $(p<0.1)$. 
A) Standardized Pereto Chart for Efficiency

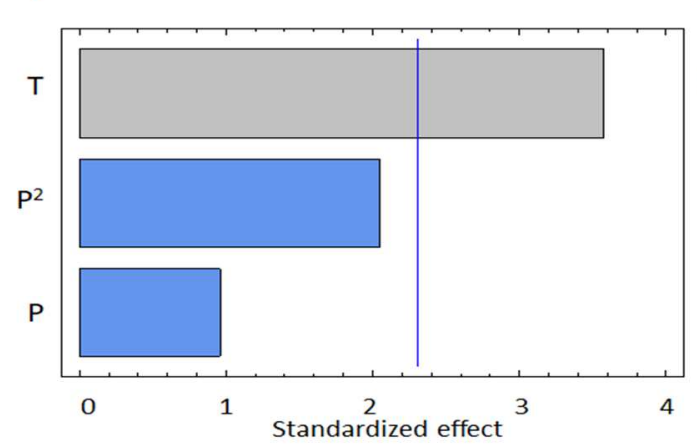

B)

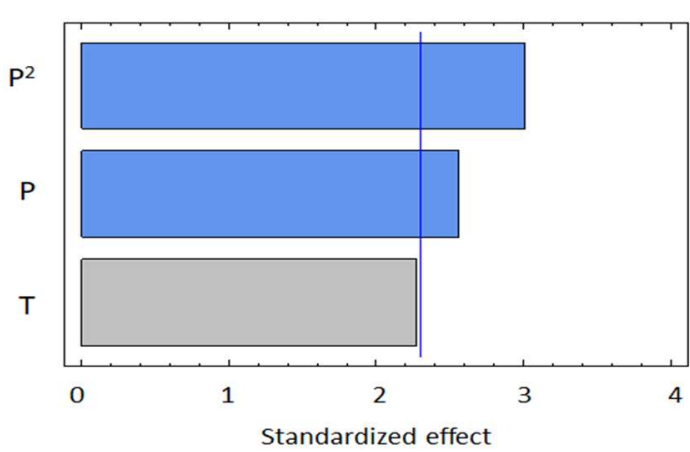

Estimated Response Surface for Efficiency

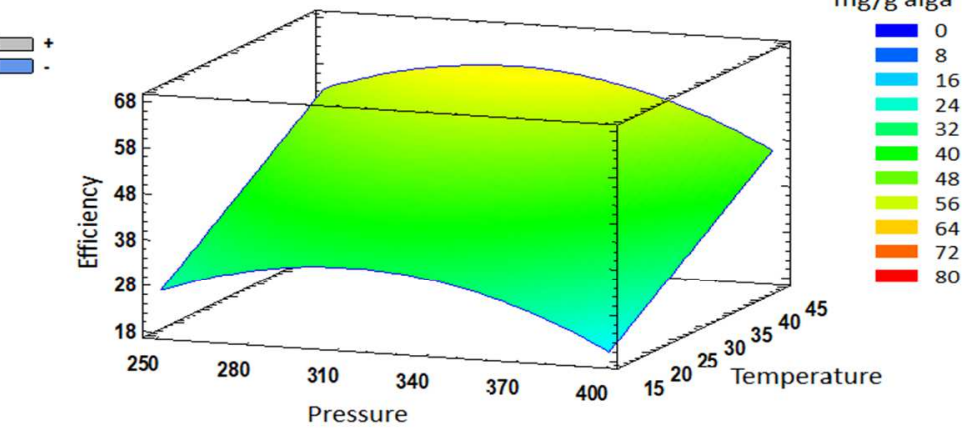

Estimated Response Surface for Purity

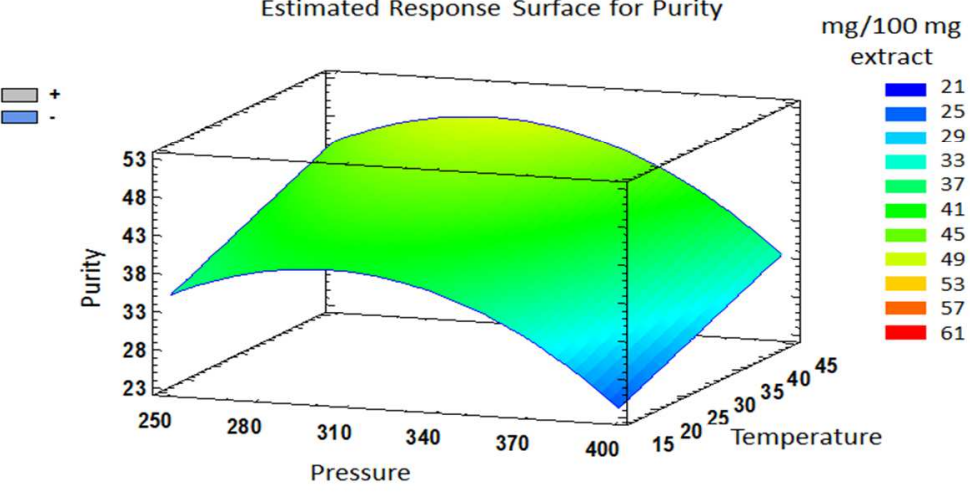

Figure 2. Pareto chart representation (left) and estimated response surface (right) of A) efficiency (mg/g alga) and B) purity (mg/100mg extract)

as a function of pressure and temperature. 
322 Despite not being the most influential factor, pressure shows an interesting behavior: up 323 to 313 bar the extraction of carotenoids is fostered by the increasing $\mathrm{CO}_{2}$ density, then

324 the trend is inverted because the solvation power cannot compensate for the decrease in 325 diffusivity. The same phenomenon can be observed in the models developed by Pour 326 Hosseini et al. ${ }^{8}$ and Macías-Sánchez et al. ${ }^{6}$. Furthermore, analyzing the response surface 327 outlined by Pour Hosseini, it is possible to notice that in our supercritical working ranges 328 of pressure and temperature, no significant impact of pressure can be expected. Thus, the results gathered in the present contribution are in agreement with the literature and a

330 plausible explanation of their behavior has been found in the physico-chemical properties 331 of $\mathrm{CO}_{2}$. Additionally, the efficiency of an extraction method does not depend entirely on 332 the solvation power of the employed solvent. For instance, the sample composition can 333 affect the outcome of the efficiency; in this sense, microalgae cultivation conditions 334 directly affect the available amount of carotenoids and other molecules present in the 335 biomass that can contribute to saturate the solvent or to interact with the compounds of 336 interest, thus, preventing the mass transfer during the extraction process ${ }^{28}$.

337 Comparisons of the results achieved under sub- and supercritical conditions with those 338 obtained by conventional extraction using acetone as solvent (Table 1) reveal than only 339 subcritical conditions ( $15^{\circ} \mathrm{C}$ extractions) are less advantageous in terms of efficiency.

340 Furthermore, SFE allows for a reduction of the extraction time from $24 \mathrm{~h}$ to $90 \mathrm{~min}$.

341 Recovery has been estimated in this work as the percentage of total carotenoids extracted

342 with respect to those extractable using a conventional extraction procedure (assumed to

343 be $100 \%$ of carotenoids). As can be seen in Table 2, the predicted values in the present work (135\% recovery) are much better than those previously reported in the literature. 
Table 2. Summary of studies on $D$. salina using $\mathrm{scCO}_{2}$ for the extraction of carotenoids.

\begin{tabular}{|c|c|c|c|c|c|c|}
\hline \multirow[b]{2}{*}{ Co-solvent } & \multicolumn{3}{|c|}{ Optimum extraction conditions } & \multicolumn{2}{|r|}{ Purity } & \multirow[b]{2}{*}{ Reference } \\
\hline & $\begin{array}{c}\text { Pressure } \\
\text { (bar) }\end{array}$ & $\begin{array}{c}\text { Temperature } \\
\left({ }^{\circ} \mathrm{C}\right)\end{array}$ & $\begin{array}{l}\text { Time } \\
(\min )\end{array}$ & $\begin{array}{l}\text { Carotenoids } \\
\text { recovery } \\
(\%)\end{array}$ & $\begin{array}{c}\text { Total } \\
\text { carotenoids } \\
(\mathrm{mg} / 100 \mathrm{mg} \\
\text { extract })\end{array}$ & \\
\hline - & 437 & 27.5 & $10+90$ & n.r. & 7.2 & [10] \\
\hline $\begin{array}{l}\text { Ethanol 5\% } \\
{[\mathrm{mol} / \mathrm{mol}]}\end{array}$ & 400 & 60.0 & 180 & 35 & n.r. & {$[6]$} \\
\hline- & 300 & 60.0 & 180 & 54 & n.r. & {$[5]$} \\
\hline- & 400 & 55.0 & 90 & 47 & n.r. & [7] \\
\hline Ethanol $5 \%[\mathrm{w} / \mathrm{w}]$ & 200 & 45.0 & 180 & n.r. & 46.0 & {$[8]$} \\
\hline- & 313 & 45.0 & 90 & 135 & - & Predicted values in this work \\
\hline - & 309 & 45.0 & 90 & - & 49.5 & Predicted values in this work \\
\hline
\end{tabular}


349 Another proposed model was designed considering the amount of carotenoids quantified per $100 \mathrm{mg}$ of extract (Table 1), which can be considered a measurement of the extract

351 purity. Extract purity is related to some applications in which the absence of other 352 interfering or non-desired components in the extracts is highly valued, independently if 353 the original biomass is completely exhausted or not. The resulting equation after 354 removing the non-significant terms of the initial model (quadratic temperature and the interaction between temperature and pressure) was (Equation 6):

where $\mathrm{Y}_{\mathrm{P}}$ stands for extract purity, $\mathrm{P}$ stands for pressure (bar) and $\mathrm{T}$ for temperature $\left({ }^{\circ} \mathrm{C}\right)$.

360 The model is able to explain $72.7 \%$ of the variation of purity and the RSD\% was

361 calculated as 5.3. The predicted optimum extraction conditions were 302.3 bar and 45.0 ${ }^{\circ} \mathrm{C}$, providing a predicted value of $49.5 \mathrm{mg}$ of carotenoids/100 mg extract. As illustrated

363 in Figure 2B, the only significant factor is pressure. In particular, the extract purity

364 correlates negatively with linear and quadratic pressure terms $(p<0.05)$, while seems to 365 have a positive trend with linear temperature $(p<0.1)$.

366 In addition to the lower environmental impact of the compressed fluid technology 367 employed, purity values obtained were always above the ones achieved using 368 conventional extractions (Table 1). Once again, the predicted purity value estimated in 369 this work (49.5 mg carotenoids/100 mg extract) is higher than the best one obtained 370 previously reported $^{9}$ (46 $\mathrm{mg}$ carotenoids/100mg extract) (Table 2). Furthermore, our extracts present the advantage of being obtained avoiding the use of ethanol as a 
cosolvent, producing a solvent-free extract potentially ready to be used, increasing the

373 sustainability of the whole process.

\section{Environmental performance of extractions}

376 There are several metrics to compare the environmental performance and impacts of

377 chemical processes. In fact, Chemat et al. ${ }^{29}$ developed a metric particularly designed for

378 extraction processes. This green metric has been recently applied to the environmental

379 impacts of compressed fluids extraction $v s$ conventional extraction process to obtain

380 antioxidants from rosemary ${ }^{30}$. Even though this and other green metrics are easy to be

381 applied, none of them are considered as standard and universal as LCA, since it provides

382 quantifiable results with a holistic view on the environmental impacts. Moreover, it is

383 based on the international standards ISO14040 and ISO14044. Therefore, in the present

384 study, the environmental performance of both studied extraction processes was compared

385 in terms of LCA.

386 Previously, Kyarialopoulou et al. ${ }^{31}$ have demonstrated that environmental impacts of

387 obtaining carotenoids from D. salina are lower than using carrots. In their work, they only

388 compared organic solvents and vegetable oil as extraction agents. Later, Espada et al. ${ }^{32}$

389 investigated the effect of supercritical $\mathrm{CO}_{2}$ extraction on the environmental impact of

390 carotenoid extraction. The novelty of our work relies on the improved results found for

391 carotenoid efficiency and yield that has been optimized using Response Surface

392 Methodology which allowed to use lower temperature with an optimal use of $\mathrm{CO}_{2}$.

393 Moreover, in the present work, the calculation method has been done following the ILCD

394 method, which joins efforts towards harmonization done by the European Commission 39521. 
396 The comparison regarding the environmental performance of supercritical $\mathrm{CO}_{2}$ vs a

397 classic SLE using acetone to obtain $1 \mathrm{~g}$ of carotenoids from D. salina (Functional Unit:

$3981 \mathrm{~g}$ of carotenoids) is shown in Figure 3. Taking into account that the aim of this LCA

399 calculation method is the comparison of processes, products or components, the values

400 are not relevant by themselves but rather they represent a comparison. Therefore, results

401 are expressed in normalized values, as impact millipoints $(\mathrm{mPt})$, in the $\mathrm{Y}$ axis. The

402 environmental impacts in the categories included for the two analyzed extraction

403 processes (SFE using $\mathrm{CO}_{2}$ and SLE using acetone) are specified in the figure. As can be

404 seen, the SFE process produces a $39 \%$ of the impacts found for SLE using the ILCD

405 calculation method.

406

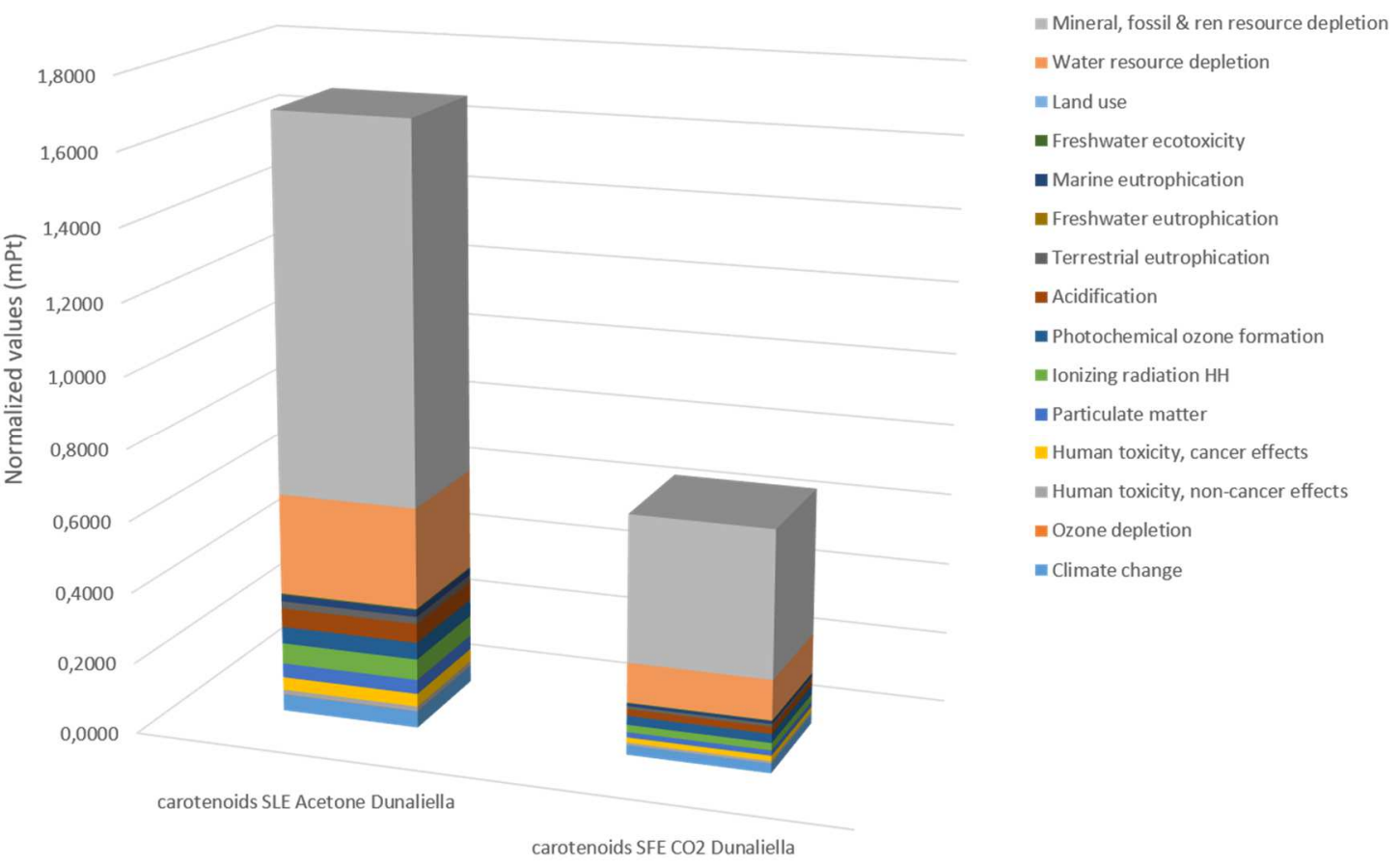

407

408 Figure 3. Impact assessment comparison of $1 \mathrm{~g}$ of $D$. salina carotenoids (FU) by SFE vs

409 SLE. Normalized values with respect to SLE. Impact values are expressed in millipoints

$410(\mathrm{mPt})$ to homogenize their values as stated in ILCD calculation method.

411 


\section{Chemical characterization of $\mathrm{CO}_{2}$ extracts from $\boldsymbol{D}$. salina}

413 Figure 4 shows an example of an HPLC chromatogram obtained for a $D$. salina extract.

414 Thanks to the information provided by their typical absorption spectra, twelve peaks were

415 assigned as carotenoids. Injection of pure standards was carried out to confirm the

416 presence of lutein, zeaxanthin, and all-trans- $\beta$-carotene (peaks 2,3 , and 9, respectively).

417 By comparison with the absorption data, elution order and retention times reported in the

418 literature $^{10,11,33}$, it was possible to identify peaks $6,7,8$, and 11 as 13 -cis- $\beta$-carotene, all-

419 trans- $\alpha$-carotene, 9 -cis- $\alpha$-carotene, and 9-cis- $\beta$-carotene, respectively. It was possible to

420 identify peak 10 as 15 -cis- $\beta$-carotene although partially co-eluted with all-trans- $\beta$ -

421 carotene, as previously reported ${ }^{11}$. This compound has two absorption maxima at 444 and $470 \mathrm{~nm}$ that differ from those of all-trans- $\beta$-carotene (452 and $478 \mathrm{~nm}$ ). Moreover, peak 5 was tentatively identified as cryptoxanthin. The capability of $D$. salina to produce cryptoxanthin has also been reported ${ }^{34}$. Peaks 1 and 4 were not identified but, being less retained than cryptoxanthin within the $\mathrm{C} 30$ column, they should be polar carotenoids and might contain at least a hydroxyl group. Therefore, in the present work, these latter components have been included for the estimation of total xanthophylls instead of total carotenes. Another remarkable piece of information emerging from the HPLC analysis is the absence of peaks in the first $10 \mathrm{~min}$ of the chromatogram acquired at $665 \mathrm{~nm}$ (data

430 not shown) which reflects the outstanding low content of chlorophylls in the $\mathrm{CO}_{2}$ extracts. 


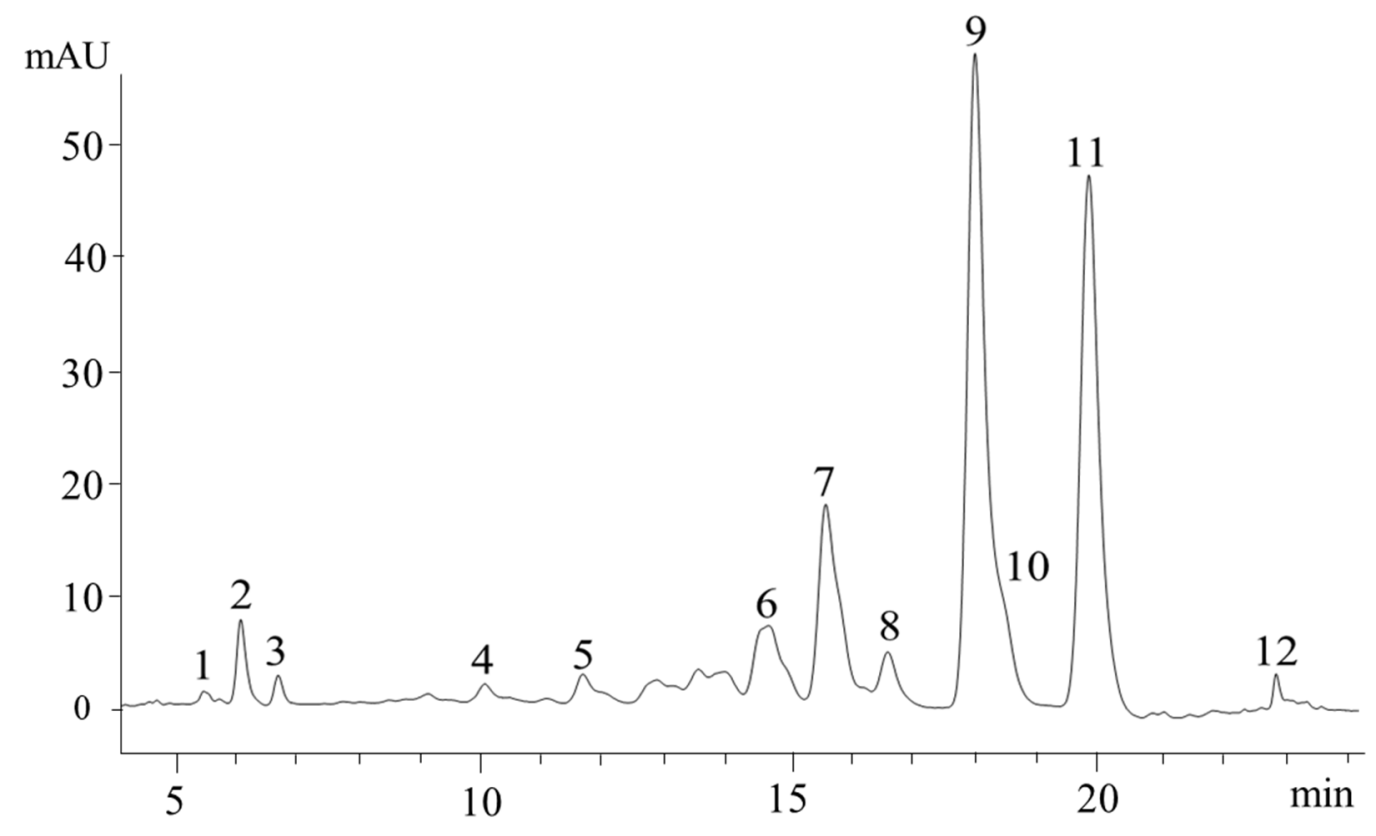

433 Figure 4. HPLC chromatogram of carotenoid extract from $D$. salina acquired at $450 \mathrm{~nm}$.

434 SFE conditions: $325 \mathrm{bar} ; 30^{\circ} \mathrm{C}$. The sample was injected at a concentration of $0.1 \mathrm{mg} / \mathrm{mL}$.

435 Peak assignment: 2, lutein; 3, zeaxanthin; 5, cryptoxanthin; 6, 13 -cis- $\beta$-carotene; 7 , all-

436 trans- $\alpha$-carotene; 8,9 -cis- $\alpha$-carotene; 9 , all-trans- $\beta$-carotene; 10,15 -cis- $\beta$-carotene; 11 ,

437 9-cis- $\beta$-carotene; 1,4 , and 12 , not identified carotenoids.

438

439 The quantitative composition of $D$. salina extracts was estimated using external standard

440 calibrations using the available commercial compounds (Table S1, Supporting

441 information). Lutein, zeaxanthin, and all-trans- $\beta$-carotene were quantified by

442 interpolation in the calibration curves created with their respective commercial standards.

443 Amounts of unidentified peak 1 were estimated using the lutein calibration curve, while

444 the zeaxanthin curve was employed for cryptoxanthin and unidentified peak 4

445 quantifications. The rest of the compounds identified as carotenes, including unidentified

446 peak 12, were quantified using the all-trans- $\beta$-carotene calibration curve, assuming a

447 similar response factor. The quantitative results related to the identified compounds are

448 reported in Table 3. As can be seen in the table, all-trans- $\beta$-carotene is the main 
449 carotenoid of $D$. salina regardless of the extraction conditions. On the other hand, 450 carotenoids represent only from 1.8 to $5.8 \%(\mathrm{w} / \mathrm{w})$ of the total composition of the alga 451 whereas the rest of the extract should be other relatively non-polar components such as 452 glycerol and other lipids ${ }^{35}$.

454 Multivariate statistical tools, including PCA, have been used to study relationships 455 between the chemical composition and the compressed $\mathrm{CO}_{2}$ extraction conditions, as 456 previously reported for yerba mate leaves ${ }^{36}$. The relationship between carotenoids levels 457 obtained in the different extraction conditions can be seen in the PCA plot illustrated in 458 Figure 5, which retains $73.84 \%$ of the original variance. As shown in that figure, PC1 459 reveals a clear separation between extraction conditions that provide $\mathrm{CO}_{2}$ densities higher 460 than $0.98 \mathrm{~g} / \mathrm{mL}$ (on the left), from the ones that provide densities lower than $0.96 \mathrm{~g} / \mathrm{mL}$ 461 (on the right). Moreover, all carotenoids have positive loadings on PC1 which, in general 462 terms, correlates lower $\mathrm{CO}_{2}$ densities with a high carotenoid extraction purity. On the 463 other hand, PC2 sorts by types of extracted carotenoids. Specifically, this PC reveals that 464 xanthophylls and 9-cis-carotenes follow a quite similar extraction pattern, while all-trans465 carotenes, 15-cis- and 13-cis- $\beta$-carotene follow a different one, being the latter group 466 more extracted at higher temperatures (extracts obtained at $45^{\circ} \mathrm{C}: 7,9,10$ ). 
467 Table 3. Carotenoid content determined in the SFE extracts from D. salina obtained at the different extraction conditions tested.

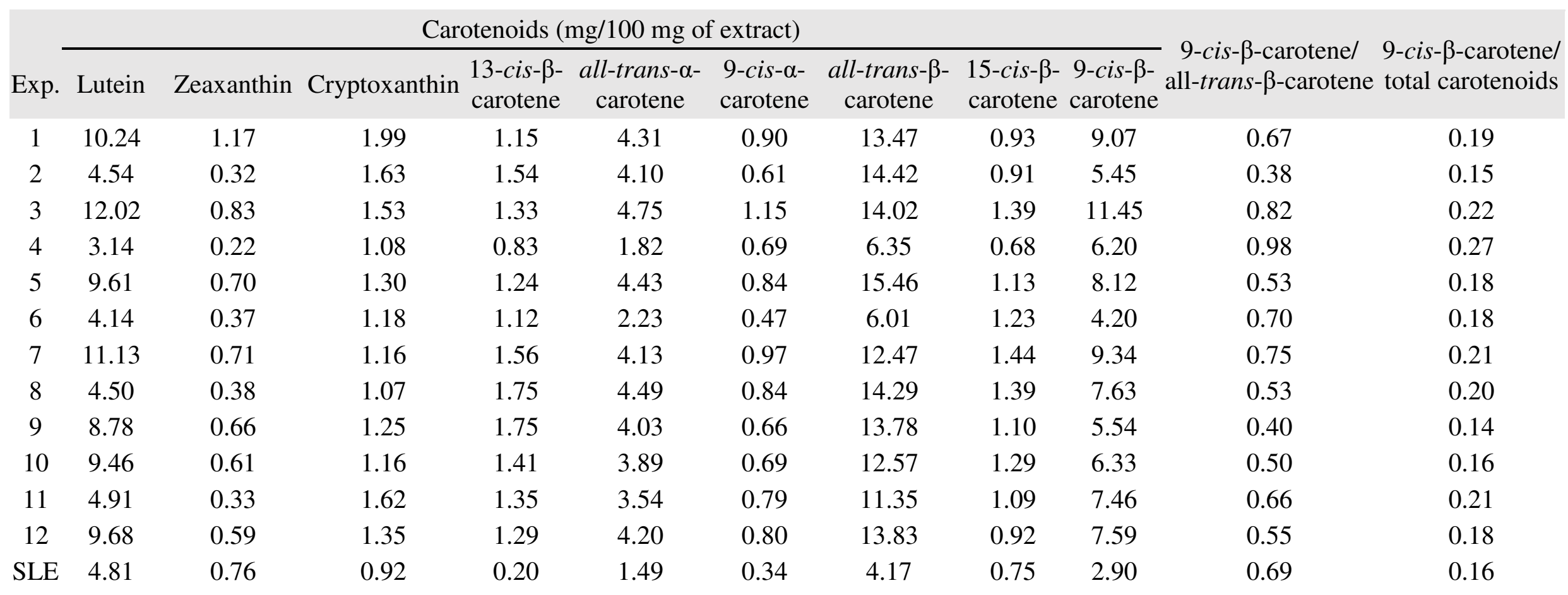

468 SLE: solid-liquid extraction 


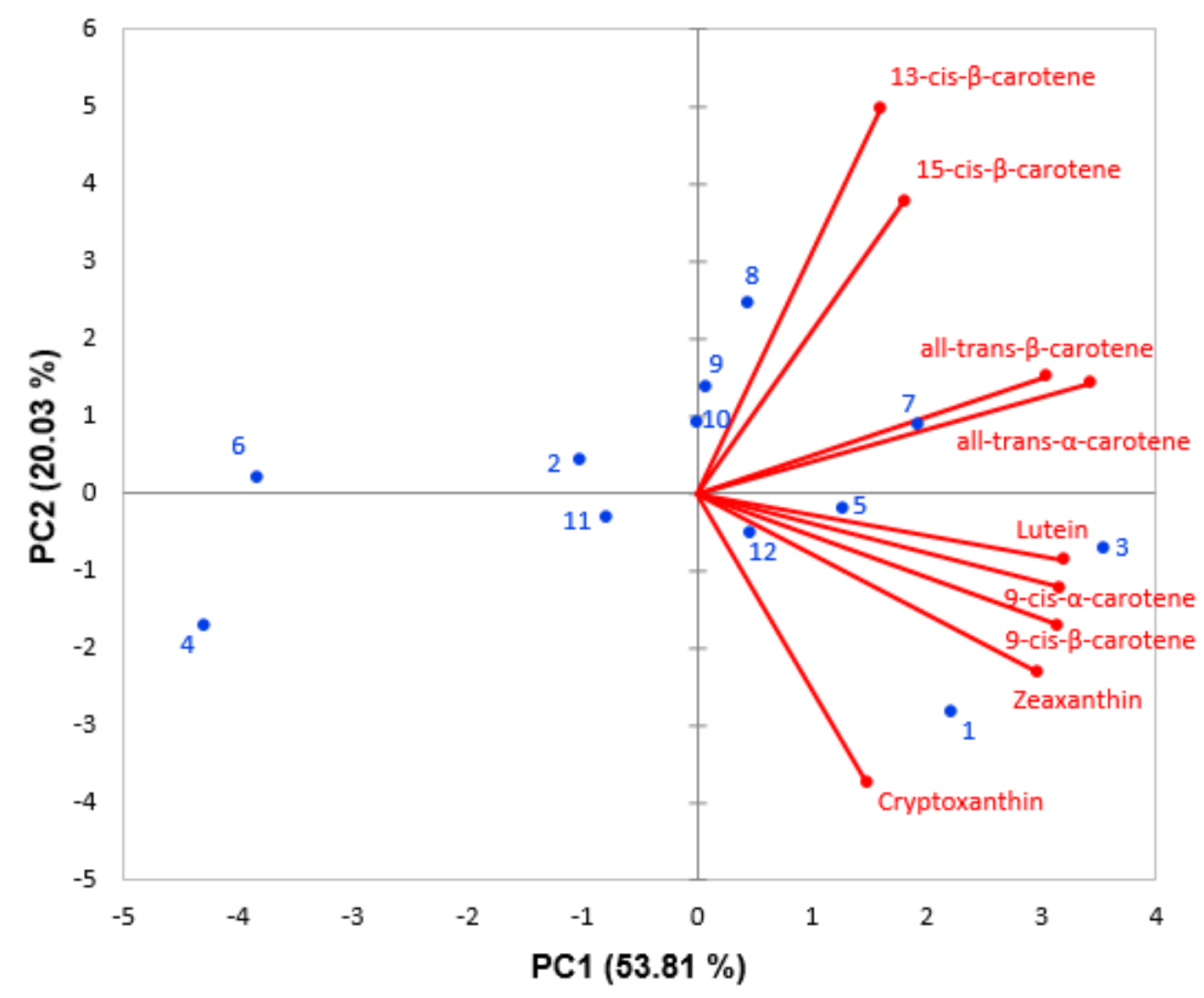

470 Figure 5. PCA plot with data of carotenoids levels obtained in the different extraction 471 conditions

\section{Modeling AChE inhibition from quantitative data}

474 As previously mentioned, microalgal carotenoids have not been previously studied 475 regarding their AChE inhibition potential. The twelve analyzed extracts were able to 476 inhibit the activity of AChE enzyme (Table 1) which can be related to positive effects 477 towards the prevention of neurodegeneration. D. salina exhibited promising inhibitory 478 properties against $\mathrm{AChE}$, with $\mathrm{IC}_{50}$ values ranging from 75 to $18 \mu \mathrm{g} / \mathrm{mL}$. As results are 479 expressed as $\mathrm{IC}_{50}$ value, the lowest the value, the highest the inhibition activity achieved. 480 The activities found were also higher than the activity provided by the extract obtained 481 using a conventional extraction procedure (SLE, Table 1). 
482 Control results from the synthetic inhibitor galantamine hydrobromide $(0.40 \pm 0.01$

$483 \mu \mathrm{g} / \mathrm{mL}$ ) were lower than $D$. salina results as expected from this specific drug.

484 Nevertheless, synthetic inhibitors are reported to have more adverse effects ${ }^{37}$ and

485 therefore, D. salina could be pointed out as a biomass of great interest to produce

486 neuroprotective natural extracts that could be subsequently used in the functional food

487 industry. In addition, it would be expected that $D$. salina extracts could present a double

488 effect against Alzheimer's disease, namely, antioxidant activity and inhibition of AChE,

489 combating two known factors of this multifactorial disease.

490 In terms of $\mathrm{AChE}$ inhibition as a single response variable, no acceptable model was

491 achieved. This lack of fit can be justified taking into consideration the different

492 quantitative data obtained in terms of carotenoids and the relative proportion of some of

493 them on the different extracts (Table 3). Nevertheless, learning about the role of the

494 different components in acetylcholinesterase activity inhibition opens a new field of

495 study. For this reason, attempts to build a model that clearly correlates and orders

496 carotenoids in relation to AChE inhibition were carried out. A satisfactory model relating

497 some quantified carotenes and xanthophylls was built using PLSR type 1 (Eq. 7).

498

$499 \mathrm{AChE} \mathrm{IC}_{50}=5.38-1.45$ lutein +2.39 zeaxanthin +6.01 cryptoxanthin -5.7715 -cis- $\beta$ -

500 carotene $+4.38(9-$ cis- $\beta$-carotene/all-trans- $\beta$-carotene $)+4.77$ (9-cis- $\beta$-carotene/total

501 carotenoids)

502

503 As can be seen in Figure 6, a reasonably good prediction of AChE inhibition was achieved

504 for all the extracts. In this plot, measured and predicted data are compared, explaining

5050.792 of the variance $(62.9 \%$ by cross-validation) and showing an RMSE for the 506 prediction of 9.729. PLS regression coefficients show a relevant positive correlation of 
507 lutein and 15-cis- $\beta$-carotene with $\mathrm{AChE}$ inhibition, as they promote lower values of $\mathrm{IC}_{50}$

508 and a negative effect of zeaxanthin and cryptoxanthin. In addition, it can be observed that

509 extracts obtained at higher temperatures (extracts $7,9,10$ ) are the ones showing lower

510 AChE IC 50 values. As observed in the PCA plot from Figure 5, these extracts contain a

511 high amount of 15 -cis- $\beta$-carotene and low amounts of zeaxanthin and cryptoxanthin. A

512 special mention should be done about the ratios 9-cis- $\beta$-carotene/all-trans- $\beta$-carotene and

513 9-cis- $\beta$-carotene/total carotenoids. In this case, the proportion of all-trans- $\beta$-carotene or

514 total carotenoid content exerted a positive effect in the inhibition of acetylcholinesterase

515 enzyme when related to 9-cis- $\beta$-carotene. The use of ratios between different carotenoids

516 has been considered in diverse bioactivity studies previously reported ${ }^{3,38}$. For instance,

517 the ratio between carotenes and xanthophylls has been stated to be different in terms of

518 anti-angiogenic activity and beauty-enhancing effects ${ }^{3}$. On the other hand, the ratio 9-cis-

$519 \beta$-carotene/all-trans- $\beta$-carotene has shown different values of antioxidant activity due to

520 the higher reactivity of the cis bond compared to the trans configuration ${ }^{38}$. It is not

521 surprising, therefore, that the proportions between two carotenes, or a carotene and the

522 total amount of carotenoids present have crucial importance in determining the

523 anticholinesterase activity of the $D$. salina extracts. Furthermore, it is quite evident the

524 key role of the ratio 9-cis- $\beta$-carotene/all-trans- $\beta$-carotene against Alzheimer's disease,

525 since on the one hand, high values promote antioxidant activity, whereas on the other 526 hand, low values improve AChE inhibition. 


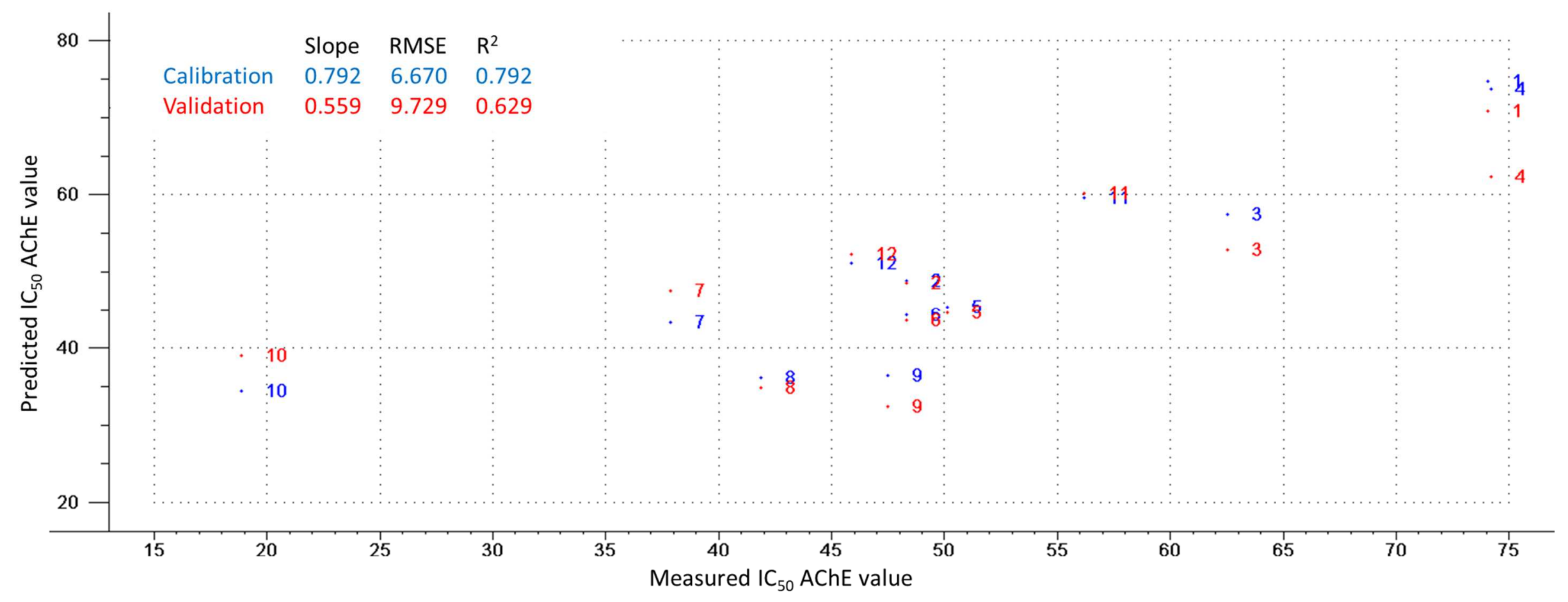

Figure 6. Plot showing predicted versus experimental $\mathrm{IC}_{50} \mathrm{AChE}$ values. Each point corresponds to an analyzed extract. 


\section{CONCLUSIONS}

532 A process based on the use of compressed carbon dioxide extraction has been optimized

533 to obtain extracts enriched in carotenoids showing potential neuroprotective activity. The

534 developed process takes advantage of the enhanced sustainability of compressed fluids,

535 particularly sub- and supercritical $\mathrm{CO}_{2}$, for the attainment of natural bioactive compounds

536 from interesting biomasses, such as microalgae. Based on the obtained data, two

537 mathematical models were designed; the most appropriate operating conditions to obtain

538 the highest carotenoid yield were set at 312.6 bar and $45.0{ }^{\circ} \mathrm{C}(60.8 \mathrm{mg}$ of carotenoids/g

539 algae). On the other hand, the optimum conditions to maximize the extract purity were

540 statistically predicted at 302.3 bar and $45.0^{\circ} \mathrm{C}(49.5 \mathrm{mg}$ of carotenoids/100 $\mathrm{mg}$ extract $)$.

541 A comparison with a conventional solvent extraction proved that the investigated green

542 method is by far better in terms of both efficiency and purity. Moreover, twelve

543 compounds were recognized as carotenoids and quantified, while nine of them were

544 identified. In addition, $D$. salina extracts exhibited promising inhibitory properties against

$545 \mathrm{AChE}$, with $\mathrm{IC}_{50}$ values ranging from 75 to $18 \mu \mathrm{g} / \mathrm{mL}$. These data along with the

546 recognized antioxidant power of $D$. salina carotenoids suggest that $D$. salina extracts

547 obtained with compressed $\mathrm{CO}_{2}$ can be used as a natural, safe and sustainable alternative

548 for future nutraceuticals or functional foods to prevent multifactorial neurological

549 pathologies such as Alzheimer's disease.

550

551 Supporting Information

552 Electronic supporting information includes: schematic representation of the system

553 used for compressed carbon dioxide extractions; Pareto chart and estimated

554 response surface of extraction yield; Carotenoid calibration curve parameters

555 obtained by HPLC-UV/Vis. 


\section{Conflicts of interest}

558 There are no conflicts to declare.

559

\section{ACKNOWLEDGEMENTS}

561 C.V. acknowledges the Erasmus+ Program for the mobility grant. J.D.S-M.

562 acknowledges the Spanish Ministry of Education, Culture and Sports (MECD) for a FPU 563 grant FPU17/01876. M.B. would like to acknowledge the Ministry of Economy and

564 Competitiveness for her "Juan de la Cierva-Formación" postdoctoral grant FJCI-2016565 30902. Authors thank projects ABACUS (Algae for a Biomass Applied to the production 566 of added value compoundS, grant agreement No 745668, funded by the Bio Based

567 Industries Joint Undertaking under the European Union's Horizon 2020 research and 568 innovation programme) and AGL2017-89417-R (MINECO, Spain) for financial support.

569 Authors also thank A4F - Algae for Future, Portugal, for supplying and assisting with 570 algae biomass.

571

572 Abbreviations

573 ABD-F: 4-(aminosulfonyl)-7-fluoro-2,1,3-benzoxadiazole

574 AChE: acetylcholinesterase

575 ATCI: acetylthiocholine iodide

576 BBB: blood-brain barrier

577 BHT: butylated hydroxytoluene

578 DAD: diode-array detector

579 DNTB: 5,5'-dithio-bis (2-nitrobenzoic acid)

580 EV\%: percentage of variance explained by the model 
581 FU: functional unit

582 ILCD: international reference life cycle data system

583 LCA: life cycle assessment

584 MLR: multiple linear regression

585 MTBE: methyl tert-butyl ether

586 NQ: not quantifiable

587 n.r.: not reported

588 PLSR: partial least square regression

589 RMSE: root-mean-square error

590 RSM: response surface methodology

591 SFE: supercritical fluid extraction

592 SLE: solid-liquid extraction

593 Tris-HCl: Trizma hydrochloride

594

595 
597 1. de Jesus Raposo, M. F.; Miranda Bernardo de Morais, A. M.; Santos Costa de Morais, R.

598 M., Carotenoids from Marine Microalgae: A Valuable Natural Source for the Prevention of 599 Chronic Diseases. Mar. Drugs 2015, 13 (8), 5128-5155. doi:10.3390/md13085128

$600 \quad 2 . \quad$ Rammuni, M. N.; Ariyadasa, T. U.; Nimarshana, P. H. V.; Attalage, R. A., Comparative 601 assessment on the extraction of carotenoids from microalgal sources: Astaxanthin from $\mathrm{H}-$ 602 pluvialis and beta-carotene from D. salina. Food Chem. 2019, 277, 128-134. 603 doi:10.1016/j.foodchem.2018.10.066

604 3. Gallego, R.; Montero, L.; Cifuentes, A.; Ibáñez, E.; Herrero, M., Green Extraction of 605 Bioactive Compounds from Microalgae. J. Anal. Test. 2018, 2 (2), 109-123. doi:10.1007/s41664606 018-0061-9

607 4. Gallego, R.; Bueno, M.; Herrero, M., Sub- and supercritical fluid extraction of bioactive 608 compounds from plants, food-by-products, seaweeds and microalgae - An update. Trends Anal. 609 Chem. 2019, 116, 198-213. doi:10.1016/j.trac.2019.04.030

$610 \quad 5 . \quad$ Sánchez-Camargo, A. d. P.; Bueno, M.; Parada-Alfonso, F.; Cifuentes, A.; Ibáñez, E., 611 Hansen solubility parameters for selection of green extraction solvents. Trends Anal. Chem. 2019, 118, 227-237. doi:10.1016/j.trac.2019.05.046

6. Macias-Sanchez, M. D.; Mantell, C.; Rodriguez, M.; de la Ossa, E. M.; Lubian, L. M.; Montero, O., Comparison of supercritical fluid and ultrasound-assisted extraction of carotenoids and chlorophyll a from Dunaliella salina. Talanta 2009, 77 (3), 948-952. doi:10.1016/j.talanta.2008.07.032

7. Macias-Sanchez, M. D.; Mantell Serrano, C.; Rodriguez Rodriguez, M.; de la Ossa, E. M.; Lubian, L. M.; Montero, O., Extraction of carotenoids and chlorophyll from microalgae with supercritical carbon dioxide and ethanol as cosolvent. J. Sep. Sci. 2008, 31 (8), 1352-1362. doi:10.1002/jssc.200700503

620

621

622

623

8. Pour Hosseini, S. R.; Tavakoli, O.; Sarrafzadeh, M. H., Experimental optimization of SCCO2 extraction of carotenoids from Dunaliella salina. J. Supercrit. Fluids 2017, 121, 89-95. doi:https://doi.org/10.1016/j.supflu.2016.11.006

624 9. Tirado, D. F.; Calvo, L., The Hansen theory to choose the best cosolvent for supercritical CO2 extraction of beta-carotene from Dunaliella salina. J. Supercrit. Fluids 2019, 145, 211-218. doi:10.1016/j.supflu.2018.12.013

627

628

629 10. Herrero, M.; Jaime, L.; Martin-Alvarez, P. J.; Cifuentes, A.; Ibáñez, E., Optimization of the extraction of antioxidants from Dunaliella salina microalga by pressurized liquids. J. Agric. Food Chem. 2006, 54 (15), 5597-5603. doi:10.1021/jf060546q

$630 \quad$ 11. Jaime, L.; Mendiola, J. A.; Ibáñez, E.; Martin-Alvarez, P. J.; Cifuentes, A.; Reglero, G.; Senorans, F. J., beta-carotene isomer composition of sub- and supercritical carbon dioxide extracts. Antioxidant activity measurement. J. Agric. Food Chem. 2007, 55 (26), 10585-10590. doi:10.1021/jf0711789

633

12. Wightman, E. L., Potential benefits of phytochemicals against Alzheimer's disease. Proceedings of the Nutrition Society 2017, 76 (2), 106-112. doi:10.1017/s0029665116002962

635

636

637

638

639

640

641 13. Akaberi, M.; Iranshahi, M.; Mehri, S., Molecular Signaling Pathways Behind the Biological Effects of Salvia Species Diterpenes in Neuropharmacology and Cardiology. Phytother. Res. 2016, 30 (6), 878-893. doi:10.1002/ptr.5599

14. Barbosa, M.; Valentao, P.; Andrade, P. B., Bioactive Compounds from Macroalgae in the New Millennium: Implications for Neurodegenerative Diseases. Mar. Drugs 2014, 12 (9), 49344972. doi:10.3390/md12094934

642 15. Kang, I.-J.; Jang, B. G.; In, S.; Choi, B.; Kim, M.; Kim, M.-J., Phlorotannin-rich Ecklonia cava 643 reduces the production of beta-amyloid by modulating alpha- and gamma-secretase expression 644 and activity. Neurotoxicology 2013, 34, 16-24. doi:10.1016/j.neuro.2012.09.013

645 16. Suganthy, N.; Pandian, S. K.; Devi, K. P., Neuroprotective effect of seaweeds inhabiting 646 South Indian coastal area (Hare Island, Gulf of Mannar Marine Biosphere Reserve): 
647 Cholinesterase inhibitory effect of Hypnea valentiae and Ulva reticulata. Neurosci. Lett. 2010, $648468(3), 216-219$. doi:10.1016/j.neulet.2009.11.001

649 17. Sánchez-Martínez, J. D.; Bueno, M.; Álvarez-Rivera, G.; Tudela, J.; Ibáñez, E.; Cifuentes,

650 A., Terpenoids-rich extracts from industrial orange by-products with neuroprotective 651 properties: Comprehensive phytochemical profiling and in-vitro bioactivity assessment. Under 652 preparation 2020.

653 18. Winther, J. R.; Thorpe, C., Quantification of thiols and disulfides. BBA - Gen. Subjects 6542014,1840 (2), 838-846. doi:10.1016/j.bbagen.2013.03.031

655 19. Craft, N. E.; Haitema, T. B.; Garnett, K. M.; K.A., F.; C.K., D., Carotenoid, tocopherol, and retinol concentrations in elderly human brain. J. Nutr. Health Aging 2004, 8 (3), 156-162.

20. Reyes, F. A.; Mendiola, J. A.; Ibanez, E.; del Valle, J. M., Astaxanthin extraction from Haematococcus pluvialis using CO2-expanded ethanol. J. Supercrit. Fluids 2014, 92, 75-83. doi:10.1016/j.supflu.2014.05.013

659

660 21. EuropeanCommission, J. R. C., International Reference Life Cycle Data System (ILCD)

661

662 Handbook- Recommendations for Life Cycle Impact Assessment in the European context. First ed.; Publications Office of the European Union: Luxemburg, 2011.

663

664

665

666

667

668

669 22. Chemat, F.; Abert Vian, M.; Fabiano-Tixier, A.-S.; Nutrizio, M.; Rezek Jambrak, A.; Munekata, P. E. S.; Lorenzo, J. M.; Barba, F. J.; Binello, A.; Cravotto, G., A review of sustainable and intensified techniques for extraction of food and natural products. Green Chemistry 2020, 22 (8), 2325-2353. doi:10.1039/c9gc03878g

23. Boussiba, S.; Vonshak, A., Astaxanthin accumulation in the green-alga Haematococcus pluvialis. Plant and Cell Physiology 1991, 32 (7), 1077-1082. doi:10.1093/oxfordjournals.pcp.a078171

670 24. Li, J.; Li, C.; Lan, C. Q.; Liao, D., Effects of sodium bicarbonate on cell growth, lipid 671 accumulation, and morphology of Chlorella vulgaris. Microbial Cell Factories 2018, 17, 111. 672 doi:10.1186/s12934-018-0953-4

673 25. Pruvost, J.; Van Vooren, G.; Le Gouic, B.; Couzinet-Mossion, A.; Legrand, J., Systematic 674 investigation of biomass and lipid productivity by microalgae in photobioreactors for biodiesel 675 application. Bioresour. Technol. 2011, 102 (1), 150-158. doi:10.1016/j.biortech.2010.06.153

676 26. Cocero, M. J.; Gonzalez, S.; Perez, S.; Alonso, E., Supercritical extraction of unsaturated 677 products. Degradation of beta-carotene in supercritical extraction processes. J. Supercrit. Fluids 678 2000, 19 (1), 39-44. doi:10.1016/s0896-8446(00)00077-2

679 27. Johannsen, M.; Brunner, G., Solubilities of the fat-soluble vitamins A, D, E, and K in 680 supercritical carbon dioxide. J. Chem. Eng. Data 1997, 42 (1), 106-111. doi:10.1021/je960219m 681 28. Saini, R. K.; Keum, Y.-S., Carotenoid extraction methods: A review of recent developments. Food Chem. 2018, 240, 90-103. doi:10.1016/j.foodchem.2017.07.099 29. Chemat, F.; Vian, M. A.; Cravotto, G., Green Extraction of Natural Products: Concept and Principles. Int. J. Mol. Sci. 2012, 13 (7), 8615-8627. doi:10.3390/ijms13078615

30. Hirondart, M.; Rombaut, N.; Fabiano-Tixier, A. S.; Bily, A.; Chemat, F., Comparison between Pressurized Liquid Extraction and Conventional Soxhlet Extraction for Rosemary Antioxidants, Yield, Composition, and Environmental Footprint. Foods (Basel, Switzerland) 2020, 9 (5), 584. doi:10.3390/foods9050584

31. Kyriakopoulou, K.; Papadaki, S.; Krokida, M., Life cycle analysis of beta-carotene extraction techniques. J. Food Eng. 2015, 167, 51-58. doi:10.1016/j.jfoodeng.2015.03.008

32. Espada, J. J.; Perez-Antolin, D.; Vicente, G.; Bautista, L. F.; Morales, V.; Rodriguez, R., Environmental and techno-economic evaluation of beta-carotene production from Dunaliella salina. A biorefinery approach. Biofuel Bioprod. Biorefin. 2020, 14 (1), 43-54. doi:10.1002/bbb.2012

33. Hu, C.-C.; Lin, J.-T.; Lu, F.-J.; Chou, F.-P.; Yang, D.-J., Determination of carotenoids in Dunaliella salina cultivated in Taiwan and antioxidant capacity of the algal carotenoid extract. Food Chem. 2008, 109 (2), 439-446. doi:10.1016/j.foodchem.2007.12.043 
698 34. Abd El-Baky, H. H.; El Baz, F. K.; El-Baroty, G. S., Production of antioxidant by the green 699 alga Dunaliella salina. Int. J. Agric. Biol. 2004, 6 (1), 49-57.

$700 \quad 35 . \quad$ Monte, J.; Ribeiro, C.; Parreira, C.; Costa, L.; Brive, L.; Casal, S.; Brazinha, C.; Crespo, J. G., 701 Biorefinery of Dunaliella salina: Sustainable recovery of carotenoids, polar lipids and glycerol. 702 Bioresour. Technol. 2020, 297, 122509. doi:https://doi.org/10.1016/j.biortech.2019.122509

703 36. Teofilovic, B.; Grujic-Letic, N.; Kovacevic, S.; Podunavac-Kuzmanovic, S.; Gadzuric, S., 704 Analysis of operating variables for yerba mate leaves supercritical carbon dioxide extraction. 705 Chem. Ind. Chem. Eng. Q. 2018, 24 (3), 231-238. doi:10.2298/ciceq170217035t

706 37. Schulz, V., Ginkgo extract or cholinesterase inhibitors in patients with dementia: What 707 clinical trials and guidelines fail to consider. Phytomedicine 2003, 10, 74-79. doi:10.1078/1433708 187x-00302

709 38. Borowitzka, M. A., Pharmaceuticals and agrochemicals from microalgae. In Chemicals 710 from microalgae, Cohen, Z., Ed. London, 1999; pp 313-352.

711

712 


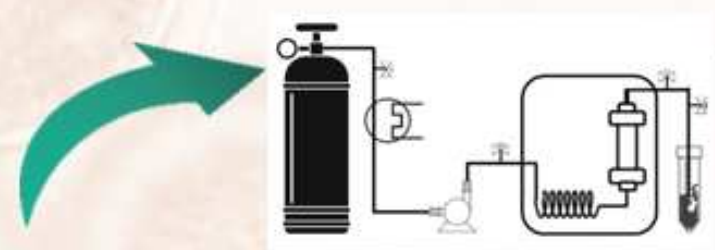

green extraction

\section{D. salina}

716

717 The use of sub- and supercritical $\mathrm{CO} 2$ is a green extraction procedure to increase

718 sustainability towards the extraction of natural compounds from Dunaliella salina

719 microalga with interesting neuroprotective activity. 